\title{
Caracterización de bacterias oxidadoras de amonio aisladas del humedal de la planta de tratamiento de aguas residuales de la Universidad de Boyacá
}

Characterization of bacteria ammonium oxidizing isolated from wetland plant wastewater treatment at Universidad de Boyaca

JOSÉ CASTELLANOS-ROZO

Microbiólogo

MSc Microbiología

Grupo de Investigación en Gestión Ambiental Universidad de Boyacá, Colombia joscastellanos@uniboyaca.edu.co

YADI JOHAIRA RAMOS-PARRA

Ingeniera Sanitaria

Especialista en Sistemas Integrados de Gestión QHSE

Grupo de Investigación en Gestión Ambiental

Universidad de Boyacá, Colombia

yjramos@uniboyaca.edu.co 


\section{RESUMEN}

El objetivo de este trabajo fue caracterizar bacterias oxidadoras de amonio (BOA) aisladas del humedal de flujo subsuperficial de la planta de tratamiento de aguas residuales de la Universidad de Boyacá. Para ello, se realizaron diluciones de muestras de suelo, las cuales fueron enriquecidas con caldo amonio e incubadas durante 28 días a $30^{\circ} \mathrm{C}$. De los tubos con reacción positiva para nitritos, se aislaron bacterias en medio mínimo de sales minerales con amonio como única fuente de nitrógeno. Se obtuvieron 16 aislamientos, los cuales se caracterizaron macroscópica, microscópica, y bioquímicamente. De los 16 aislamientos obtenidos, tan solo 4 tuvieron la capacidad de crecer rápidamente en medio amonio sólido, durante 28 días a $30^{\circ} \mathrm{C}$. Estos aislamientos fueron evaluados por su capacidad de oxidar el amonio a nitrito en medio mínimo de sales minerales. Los resultados indicaron que el aislamiento A7 y A15, presentaron diferencias significativas en la oxidación del amonio con respecto a los demás aislamientos seleccionados, lo cual indica su potencial para ser utilizado en procesos de tratamiento de aguas residuales.

Palabras claves: aislamiento, nitrificación, bacteria, humedal de flujo subsuperficial, medio de amonio.

\section{ABSTRACT}

The aim of this work was to isolate and characterize ammonium oxidizing bacteria (BOA) of a subsurface flow wetland plant wastewater treatment at the Universidad de Boyacá. For this purpose, soil sample dilutions were made, which were enriched with ammonium broth and incubated for 28 days at $30^{\circ} \mathrm{C}$. From tubes with positive reaction for nitrite, bacteria were isolated on minimal medium with ammonium as the sole nitrogen source. 16 isolates were obtained, which were characterized macroscopic, microscopic, and biochemically. Of the 16 isolates obtained, only 4 had the ability to grow rapidly in solid ammonium medium for 28 days at $30^{\circ} \mathrm{C}$. These isolates were tested for their ability to oxidize ammonium to nitrite in minimal mineral salts medium. The results indicated that isolation A7 and A15 showed significant differences in the oxidation of ammonia with respect to the other selected isolates, which indicates its potential to be used in treatment processes of wastewater.

Keywords: isolation, nitrification, bacteria, subsurface flow wetland, ammonium medium. 


\section{INTRODUCCIÓN}

Los humedales son depuradores de alta eficiencia del agua residual y representan inversiones de bajo costo en construcción, operación y mantenimiento, a diferencia de los métodos convencionales (Otálora, 2011). Se ha comprobado en diferentes estudios la capacidad que tienen los humedales para remover del agua residual cantidades significativas de materia orgánica, nitrógeno, fósforo, sólidos suspendidos, microorganismos patógenos y metales pesados (Contreras et al. 2009, Chaparro y Ospina 2005). Esta capacidad es atribuida a la diversidad biológica que poseen, especialmente a los microorganismos, los cuales a través de su metabolismo son capaces de transformar y remover los compuestos químicos contaminantes del agua residual, utilizándolos como fuente de carbono, nitrógeno y fósforo para su crecimiento (Madigan et al., 2009).

Dentro de los principales compuestos contaminantes del agua se encuentran los nitrogenados, causantes de la eutrofización de ambientes acuáticos naturales junto con el fósforo (De Jonge et al., 2002). Tradicionalmente, se ha reportado que el nitrógeno orgánico, es transformado rápidamente en nitrógeno amoniacal por microorganismos, en presencia de oxígeno, en un proceso denominado amonificación. Posteriormente el nitrógeno amoniacal es oxidado por microorganismos quimiolitótrofos a su forma nítrica en dos pasos, el primero se denomina nitritación, el cual consiste en la oxidación del amonio $\left(\mathrm{NH}_{4}^{+}\right)$a nitrito $\left(\mathrm{NO}_{2}^{-}\right)$, por bacterias oxidadoras de amonio (BOA), como Nitrosomonas sp., Nitrosovibrio sp., Nitrosococcus sp., Nitrosolobus sp., Nitrosospira sp. (Kouki et al., 2011). El segundo paso es la nitratación, que es la conversión del nitrito $\left(\mathrm{NO}_{2}^{-}\right)$a nitrato $\left(\mathrm{NO}_{3}{ }^{-}\right)$, este proceso es realizado por bacterias oxidadoras de nitrito (BON), como Nitrobacter sp., Nitrococcus sp, y Nitrospira sp. (APHA et al., 2012, Holt et al., 1994). La nitrificación disminuye la toxicidad de los metabolitos nitrogenados, porque el nitrato es menos tóxico y puede ser asimilado por las plantas y por los microorganismos de los humedales y convertidos en proteínas. También puede ser convertido en $\mathrm{N}_{2}, \mathrm{~N}_{2} \mathrm{O} \mathrm{NO}_{2}$ y $\mathrm{NO}$ en condiciones anaeróbicas en un proceso denominado desnitrificación.

El metabolismo quimiolitótrofo, no es la única forma en la cual los microorganismos pueden llevar a cabo la nitrificación. Estudios recientes han determinado la capacidad de algunos aislamientos microbianos, para llevar a cabo la eliminación del amonio, del nitrito y del nitrato por nitrificación heterótrofa y desnitrificación aeróbica (Padhi et al., 2013; Chen et al., 2012; Qiu et al., 2012; Zhang et al., 2011; Zhao et al., 2010 y Kim et al., 2005). Las bacterias nitrificantes quimiolitótrofas y quimioheterótrofas podrían ser utilizadas para disminuir costos y hacer más eficientes los tratamientos de aguas residuales. El objetivo de este trabajo fue caracterizar bacterias oxidadoras de amonio, aisladas del humedal de flujo subsuperficial de la planta de tratamiento de aguas residuales de la Universidad 
de Boyacá, seleccionarlas por su crecimiento y determinar la capacidad que tienen para remover amonio en condiciones in vitro.

\section{METODOLOGÍA}

\section{Caracterización de microorganismos nitrificantes}

Se colectaron muestras de suelo del humedal, como se describe en Ramos et al., 2014. Se adicionaron $10 \mathrm{~g}$ de suelo de cada muestra, en frascos con $90 \mathrm{~mL}$ de solución de $\mathrm{NaCl} 0,85 \%$ estéril, con el objeto de hacer diluciones seriadas de acuerdo a la metodología descrita por Madigan et al., 2009. Posteriormente se sembró $1 \mathrm{~mL}$ de cada dilución realizada, por triplicado en tubos de ensayo con caldo amonio estéril, cuya composición fue la siguiente $(\mathrm{g} / \mathrm{L}):\left(\mathrm{NH}_{4}\right)_{2} \mathrm{SO}_{4}, 0,15 ; \mathrm{CaCO}_{3}, 1,0 ; \mathrm{KH}_{2} \mathrm{PO}_{4}, 1,0 ; \mathrm{MgSO}_{4}$ * $7 \mathrm{H}_{2} \mathrm{O}, 0,3 ; \mathrm{NaCl}, 0,3 ; \mathrm{FeSO}_{4}, 0,03$ y $950 \mathrm{~mL}$ de agua destilada, pH 7,8 (Rodríguez et al. 2007). Los tubos se incubaron a $30^{\circ} \mathrm{C}$, durante 28 días en oscuridad y luego fueron revelados con el reactivo de Griess y polvo de Zinc, para evidenciar cualitativamente la oxidación del amonio a nitrito. De los tubos con reacción positiva para nitritos, se tomaron alícuotas de $0,1 \mathrm{~mL}$, las cuales fueron sembradas sobre la superficie de cajas de Petri, que contenían medio sólido con amonio como única fuente de nitrógeno. Las cajas se incubaron durante 28 días a $30^{\circ} \mathrm{C}$. Pasado el tiempo de incubación, se realizaron repiques sucesivos, mediante siembras por aislamiento, en medio sólido con amonio como única fuente de nitrógeno, hasta obtener cultivos puros (Madigan et al., 2009; Rodríguez et al., 2007). Se realizó la descripción de las características macroscópicas, microscópicas y bioquímicas, para cada aislamiento según Holt et al., (1994) y la selección de los aislamientos que presentaron crecimiento a $30^{\circ} \mathrm{C}$ en oscuridad a los 28 días en medio mínimo sólido con amonio como única fuente de nitrógeno, pH 7,8 (Rodríguez et al., 2007).

\section{Cuantificación de la capacidad oxidadora de amonio}

Los aislamientos bacterianos seleccionados fueron sembrados masivamente, en medio sólido con amonio como única fuente de nitrógeno. Se tomó la biomasa de cada aislamiento y se depositó en tubos con $\mathrm{NaCl}$ al $0,85 \%$. Luego fue homogenizada con un agitador por 5 segundos y ajustada hasta obtener una absorbancia de 0,5 a $600 \mathrm{~nm}$. Posteriormente, $10 \mathrm{~mL}$ de la biomasa fueron inoculados en erlenmeyers con $90 \mathrm{~mL}$ de caldo amonio (pH 7,8) (Rodríguez et al., 2007). Los cultivos inoculados se incubaron a $30^{\circ} \mathrm{C}$, con agitación constante de $150 \mathrm{rpm}$ durante 28 días y en oscuridad. Pasado este tiempo, se empleó el método de destilación preliminar $4500-\mathrm{NH}_{3}$ para cuantificar el consumo de amonio (APHA et al., 2012). Como control negativo se utilizó caldo amonio sin inóculo microbiano. Todo el experimento fue realizado por triplicado.

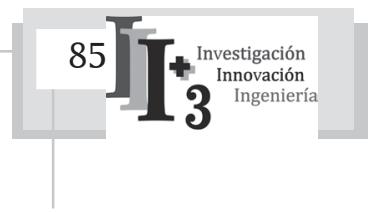




\section{Análisis estadístico}

Se realizó la prueba de normalidad y homogeneidad de varianza. Posteriormente se realizó un ANOVA a una vía con un valor de significancia del $0,05 \%$. Para determinar diferencias significativas entre el control (caldo amonio sin inóculo) y los tratamientos con inóculo bacteriano, se aplicó la prueba de Dunnett. Para determinar diferencias entre los aislamientos microbianos se empleó la prueba DSM (Diferencias Mínimas Significativas), utilizando el programa SPSS versión 1.8.

\section{RESULTADOS Y DISCUSIÓN}

\section{Caracterización de los microorganismos nitrificantes}

Se obtuvieron 16 aislamientos bacterianos, los cuales fueron caracterizados. La mayoría presentaron colonias pequeñas, con formas regulares, generalmente traslúcidas y mucoides. Se observó que los aislamientos A1, A5, A11 y A15, en los cultivos de enriquecimiento, formaron agregaciones celulares o flóculos, lo cual concuerda con lo descrito por Holt y colaboradores (1994), donde las BOA, así como las BON, se agregan en microcolonias denominados flóculos o quistes. Las células en estos agregados producen sustancias exopoliméricas (EPS), que pueden proteger a los organismos contra sustancias tóxicas y las condiciones ambientales cambiantes. Esta propiedad que tiene los microorganismos facilitan los procesos de decantación y filtración en el tratamiento de aguas de origen superficial, servidas, domésticas, industriales y de minería.

Con respecto a las características microscópicas se observó que los aislamientos A10, A11, presentaron morfología de bacilos Gram positivos, mientras que los demás aislamientos A2, A4, A5, A7, A8, A9 y A13, presentaron morfología de bacilos Gram negativos. Además de ello, se observaron bacterias pleomórficas como los aislamientos A3, A12, A14, A15 y A16 (ver Tabla 1).

\begin{tabular}{|c|c|c|c|c|c|c|c|c|c|c|c|c|c|c|c|c|}
\hline CARACTERÍSTICAS & A1 & $\mathrm{A} 2$ & A3 & A4 & A5 & A6 & A7 & A8 & A9 & A10 & A11 & A12 & A13 & A14 & A15 & A16 \\
\hline \multirow{6}{*}{ MACROSCÓPICAS } & EC & EP & EC & $\mathrm{EP}$ & EP & EP & EC & $\mathrm{EC}$ & EP & EP & EC & EP & $\mathrm{EC}$ & EP & EP & EP \\
\hline & BR & BL & $\mathrm{BR}$ & $\mathrm{BL}$ & BR & $\mathrm{BR}$ & BR & $\mathrm{BD}$ & $\mathrm{BL}$ & BL & BL & $\mathrm{BL}$ & BR & $\mathrm{BR}$ & $\mathrm{BR}$ & BL \\
\hline & $\mathrm{AB}$ & AT & AT & AT & $\mathrm{AB}$ & $\mathrm{AO}$ & $\mathrm{AB}$ & $\mathrm{AB}$ & $\mathrm{AB}$ & AT & $\mathrm{AO}$ & $\mathrm{AB}$ & $\mathrm{AB}$ & $\mathrm{AB}$ & $\mathrm{AB}$ & $\mathrm{AO}$ \\
\hline & $\mathrm{CM}$ & $\mathrm{CB}$ & $\mathrm{CB}$ & $\mathrm{CB}$ & $\mathrm{CM}$ & $\mathrm{CB}$ & $\mathrm{CM}$ & $\mathrm{CB}$ & $\mathrm{CD}$ & СB & $\mathrm{CM}$ & $\mathrm{CB}$ & $\mathrm{CB}$ & $\mathrm{CB}$ & $\mathrm{CM}$ & $\mathrm{CB}$ \\
\hline & PB & PG & PG & PG & PB & PB & PAV & PB & PAV & PB & PT & PB & PB & PAV & PAV & PB \\
\hline & OP & OP & OP & OP & SO & $\mathrm{OP}$ & OP & SO & OP & OP & OS & SO & OS & OS & OS & OS \\
\hline Microscópicas & BGPL & BGNL & CBGN & BGN & BGNL & BGPC & BGN & BGNL & BGNL & BGPL & DCGP & CBGP & BGNC & CBGN & BCGN & BGNC \\
\hline
\end{tabular}

Tabla 1. Características microscópicas y macroscópicas de los aislamientos obtenidos 
Características macroscópicas: $\mathrm{AB}$ : aspecto Brillante, $\mathrm{AO}$ : aspecto opaco, AT: aspecto traslucido, BD: borde definido, BL: borde lobulado, BR: borde regular, CB: consistencia blanda, CD: consistencia dura, CM: consistencia mucoide, EC: elevación convexa, EP: elevación plana, OS: olor a suelo, OP: olor pútrido, PAV: pigmento amarillo verdoso, PB: pigmento Blanco, PG: pigmento gris, PT: pigmento traslucido o blanco, SO: sin olor. Características microscópicas: BGPL: bacilos Gram positivos largos, BGNL: bacilos Gram negativos largos, BCGN: bacilos cortos Gram negativos, BGN: bacilos Gram negativos, BGPC: Bacilos Gram positivos en cadena, DGP: diplococos Gram positivos, CBGP: cocobacilos Gram positivos, BGNC. Bacilos Gram negativos cortos.

Las bacterias oxidadoras del amonio (BOA), han sido aisladas de diferentes ambientes y se caracterizan por su gran diversidad morfológica. Holt y colaboradores (1994), argumentan que la morfología celular es el principal criterio taxonómico para distinguir las BOA. El género Nitrosomonas sp., que presenta morfología de bacilos cortos y largos Gram negativos, se ha aislado de suelos, aguas dulces eutrofizadas y ambientes marinos. Los representantes del género Nitrosovibrio sp., cuya morfología es de bacilos curvos Gram negativos, se han aislado principalmente de suelos, rocas y agua dulce. Cocos Gram negativos como Nitrosococcus sp., viven en el suelo y en ambientes marinos, bacterias con forma de espiral como Nitrosospira sp., o pleomórficas lobulares Gram negativas como Nitrosolobus sp., habitan en el suelo.

Además se pudo observar, que todos los aislamientos presentaron movilidad (ver tabla 2). Es aceptado por varios autores que las BOA, son móviles con flagelos perítricos, polares o subpolares (Holt el al., 1994). También se observó, que todos los aislamientos con excepción del aislamiento 14, presentaron actividad catalasa positiva. No obstante, se observó que los aislamientos A4, A11 y A14 no presentan actividad oxidasa. 


\begin{tabular}{|c|c|c|c|c|c|c|c|c|c|c|c|c|c|c|c|c|}
\hline CARACTERÍSTICA & A1 & A2 & A3 & A4 & A5 & A6 & A7 & A8 & A9 & A10 & A11 & A12 & A13 & A14 & A15 & A16 \\
\hline OXIDASA & + & + & + & - & + & + & + & + & + & + & - & + & + & - & + & + \\
\hline CATALASA & + & + & + & + & + & + & + & + & + & + & + & + & - & + & + & + \\
\hline MOVILIDAD & + & + & + & + & + & + & + & + & + & + & + & + & + & + & + & + \\
\hline INDOL & + & - & - & + & - & - & - & - & - & - & - & - & - & - & - & + \\
\hline ARABINOSA & - & - & - & - & - & - & - & - & - & - & - & - & - & + & - & - \\
\hline MANOSA & + & - & - & - & - & - & - & - & - & - & - & + & - & + & - & - \\
\hline SACAROSA & + & - & - & - & - & + & + & - & - & - & - & + & - & - & - & - \\
\hline MELIBIOSA & + & - & - & - & - & + & - & - & - & - & - & - & - & - & - & - \\
\hline RHAMNOSA & - & - & - & - & - & - & - & - & - & - & - & - & - & - & - & - \\
\hline SORBITOL & - & - & - & - & - & - & - & - & - & - & - & - & - & - & - & - \\
\hline MANITOL & - & - & - & - & - & - & - & + & - & + & - & - & + & + & - & - \\
\hline ADONITOL & - & - & - & - & - & - & - & - & - & - & - & - & - & - & - & - \\
\hline GALACTOSA & - & - & - & - & - & - & + & + & - & + & - & - & + & + & - & + \\
\hline INOSITOL & - & - & - & - & - & - & + & - & - & - & - & - & - & - & - & - \\
\hline P-N-P-FOSFATO & - & + & - & + & - & - & - & - & - & - & - & - & - & + & - & - \\
\hline P-N-P-FOSFATO GLUCÓSIDO & - & + & - & + & + & - & + & - & + & - & + & - & - & + & + & - \\
\hline P-N-P-B-GALACTÓSIDO & + & + & - & - & + & - & + & - & + & - & + & - & - & + & + & - \\
\hline NITROANILIDA PROLINA & - & - & - & - & - & - & + & - & + & - & + & - & - & + & + & - \\
\hline P-N-P-DIS- FOSFATO & - & - & - & - & + & - & - & - & + & - & - & - & - & - & - & - \\
\hline P-N-P-XILÓSIDO & - & - & - & - & - & - & + & - & + & - & - & - & - & + & + & - \\
\hline P-N-P -A- ARABINÓSIDO & - & - & - & - & - & - & - & - & - & - & - & - & - & - & - & - \\
\hline P-N-P-FOSFORILCOLINA & - & - & - & - & - & - & - & - & - & - & - & - & - & - & - & - \\
\hline P-N-P-B-GLUCURÓNIDO & + & - & - & - & - & - & - & - & - & - & - & - & - & - & - & - \\
\hline P-N-P- N ACETILGLUCOSIMINIDA & - & - & + & - & - & - & + & - & - & - & - & - & - & + & - & - \\
\hline L-GLUTAMIL P-NITROANILIDA & + & + & - & - & - & - & - & - & + & - & - & - & - & + & - & - \\
\hline ESCULINA & + & + & - & + & - & - & + & - & + & - & + & - & - & + & + & - \\
\hline P-N-DL-FENILALANINA & + & - & - & - & - & + & - & - & + & - & - & - & - & - & - & - \\
\hline UREA & + & + & - & + & - & - & - & - & + & - & - & - & - & - & - & - \\
\hline GLICINA & - & + & - & + & + & - & - & - & + & - & - & - & - & - & - & - \\
\hline CITRATO & - & + & + & + & + & - & - & - & + & - & - & - & - & - & - & - \\
\hline ÁCIDO MÁLICO & - & - & - & - & - & - & - & - & - & - & - & - & - & - & - & - \\
\hline TRIFENIL TETRAZOLIO CLORURO & - & + & + & + & + & - & - & - & - & - & - & - & - & - & - & - \\
\hline ARGININA & - & + & + & + & + & - & - & - & + & - & - & - & - & - & - & - \\
\hline LISINA & - & - & - & - & - & - & - & - & - & - & - & - & - & - & - & - \\
\hline
\end{tabular}

Tabla 2. Características bioquímicas de los aislamientos obtenidos 
Por otra parte, se determinó que los aislamientos obtenidos tienen metabolismo quimiolitótrofo, presentan una tasa de crecimiento lenta, su temperatura y $\mathrm{pH}$ de crecimiento óptimos son de $30^{\circ} \mathrm{C} \mathrm{y}$ 7,8 respectivamente. También se pudo comprobar que los aislamientos obtenidos, tienen una capacidad limitada para asimilar compuestos orgánicos como azúcares. No obstante, crecen en medios de cultivo como agares sangre, chocolate y nutritivo a $25^{\circ} \mathrm{C}$ durante $48 \mathrm{~h}$. Estos resultados coinciden con lo reportado por Kouki et al., (2011), APHA et al., (2012), sección 9245 A y Holt et al., 1994., en la cual bacterias implicadas en el proceso de nitrificación presentan metabolismo mixótrofo.

Algunos de los aislamientos obtenidos también presentaron características similares al aislamiento obtenido de una biopelícula del disco de rotación, en el tratamiento de lixiviados en una planta de vertedero en Mechernich, Alemania (Lukow y Diekmann; 1997). La bacteria presentó colonias redondas translúcidas, de aspecto húmedo. Como características microscópicas, se observaron bacilos ligeramente curvados, Gram negativos (0,75 mm de diámetro y 1,5-2,0 $\mathrm{mm}$ de largo), móvil por un flagelo polar. Como características bioquímicas se observó que hidroliza la gelatina, presentó reacción oxidasa positiva y catalasa débilmente positiva. Se evidenció que escasamente asimila azúcares. Además se determinó que no pudo utilizar el metanol pero si el acetato, propionato, butirato, y etanol como fuentes de carbono.

En la Tabla 2 también se evidencia la capacidad que tienen los aislamientos A1, A2, A4 y A9, para hidrolizar la urea a amonio y utilizarla como fuente de nitrógeno. Según Holt et al., (1994), se ha determinado que la urea puede ser hidrolizada y ser utilizada como fuente de amonio por muchas, pero no todas, las BOA. También se ha dicho que la actividad ureasa, es importante para los oxidantes del amonio, que viven en suelos ácidos ( $\mathrm{pH} 4$ ), porque los protege de condiciones adversas.

\section{Cuantificación de la capacidad oxidadora de amonio}

Algunos oxidantes de amonio tienen tiempos de generación muy prolongados, lo cual dificulta el aislamiento y caracterización porque se puede demorar varios meses, para obtener cultivos puros (Holt et al., 1994). Por tal razón, se seleccionaron los aislamientos A1, A2, A7 y A15, teniendo como criterio de selección su rápido crecimiento en medio mínimo sólido con amonio como fuente de nitrógeno, durante 28 días de incubación a $30^{\circ} \mathrm{C}$.

$\mathrm{Al}$ evaluar los 4 aislamientos seleccionados por su capacidad para oxidar el amonio bajo las mismas condiciones de laboratorio, el análisis estadístico determinó con un a 0,05\% diferencias significativas entre todos los aislamientos y el tratamiento control, lo cual indica que hubo oxidación del amonio, por los aislamientos bacterianos. Además, se demostró que los aislamientos A7 y A15, fueron significativamente diferentes a los aislamientos A1 y A2, al presentar mayor oxidación del amonio, como se presenta en la Figura 1. 


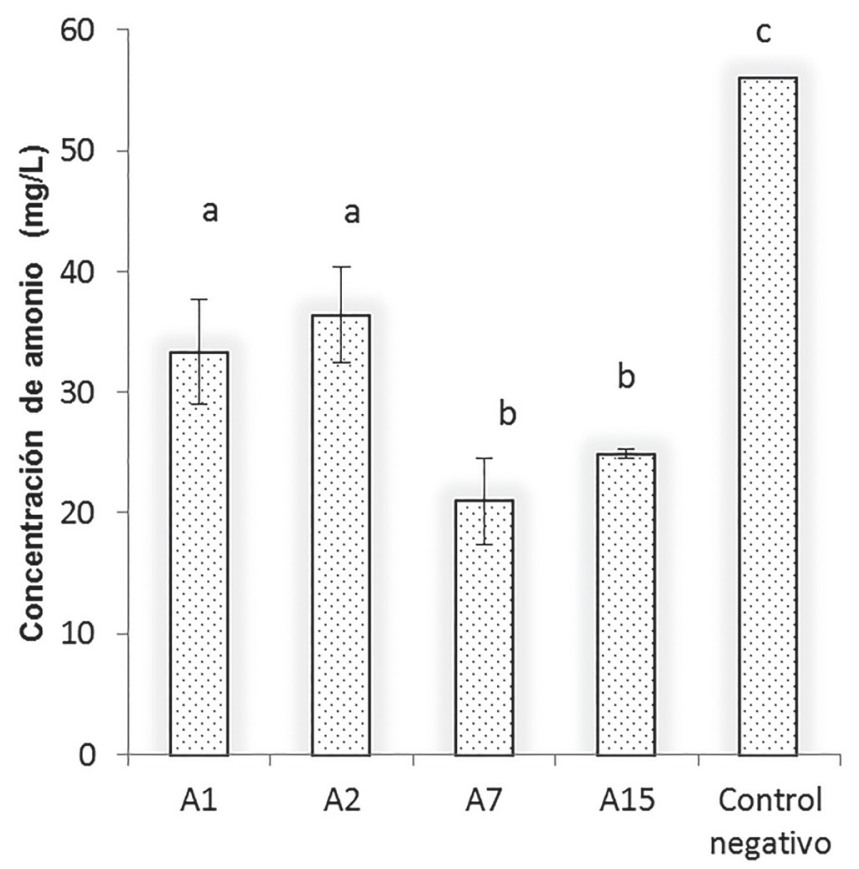

Aislamientos bacterianos obtenidos del humedal

Figura 1. Evaluación del consumo de amonio a partir de los aislamientos obtenidos del humedal de flujo subsuperficial de la planta de tratamiento de agua residual de la Universidad de Boyacá.

Como control negativo se empleó medio mínimo de amonio como única fuente de nitrógeno sin bacteria. $n=3$. Letras distintas indican diferencias estadísticamente significativas. Los intervalos sobre cada barra representan la desviación estándar.

Se ha determinado que las tasas de oxidación del amonio son diferentes entre los subgrupos de las BOA. Las tasas altas de oxidación están asociadas al inusual contenido de citocromos que se encuentran en el espacio periplasmático y en la membrana celular de las bacterias (Holt et al., 1994).

Por otro lado, se ha determinado que los valores de oxidación del amonio, son menores en microrganismos con actividad ureasa. De acuerdo a los resultados obtenidos en este estudio, los aislamientos A7 y A15, no tienen actividad ureasa y presentan mayor oxidación del amonio, mientras los aislamientos A1 y A2 presentan actividad ureasa y una menor oxidación del amonio, lo cual concuerda con lo descrito en la literatura. Dentro de los géneros que presentan actividad ureasa negativa, se encuentra principalmente el género Nitrosomonas sp. Específicamente se destacan los linajes 1a, 1b y 3a. Los linajes 1a y 1b, se caracterizan por encontrarse en aguas dulces eutrofizadas y aguas salobres, mientras que los representantes del linaje 3a, viven en suelos no ácidos y son sensibles a sal (Pommerening and Koops; 2005). 
También se demostró que entre los aislamientos A7 y A15, no hubo diferencias significativas en cuanto a la oxidación del amonio. A15 y A7, tienen en común otras características, como son el color y aspecto de las colonias, la morfología bacilar Gram negativa, la actividad oxidasa y catalasa, movilidad, hidrólisis de los sustratos p-n-p-fosfato glucósido, p-n-p- $\beta$-galactósido, Nitroanilida prolina, p-n-p-xilósido y esculina. No obstante, el aislamiento A15 se diferencia del A7 por fermentar sacarosa, galactosa, inositol y ser capaz de hidrolizar el p-n-p-N-acetil glucosamidina, como se puede ver en las Tablas 1 y 2. De acuerdo a sus características ecofisiológicas, los aislamientos A15 y A7, podrían ser clasificados dentro del género Nitrosomonas sp., específicamente al linaje 3a, del cual hace parte Nitrosomonas comunis, Nitrosomonas sp. I y Nitrosomonas sp. II.

Es comúnmente aceptado que el nitrógeno inorgánico es removido por microorganismos nitrificantes autotróficos en diferentes ambientes, mediante tres pasos: el primer paso consiste en la oxidación del amonio $\left(\mathrm{NH}_{4}^{+}\right)$a nitrito $\left(\mathrm{NO}_{2}^{-}\right)$, por las BOA, como Nitrosomonas sp., Nitrosovibrio sp., Nitrosococcus sp., Nitrosolobus sp., Nitrosospira sp. (Kouki et al., 2011). El segundo paso es la conversión del nitrito $\left(\mathrm{NO}_{2}{ }^{-}\right)$ a nitrato $\left(\mathrm{NO}_{3}^{-}\right)$, proceso realizado por las BON, como Nitrobacter sp., Nitrococcus sp, y Nitrospira sp., y el tercer paso es la desnitrificación que es el paso de nitrato $\left(\mathrm{NO}_{3}^{-}\right)$a óxido nitroso $\left(\mathrm{NO}_{2}\right)$ y nitrógeno molecular $\left(\mathrm{N}_{2}\right)$, conversión llevada a cabo por géneros como Pseudomonas denitrificans y Paracoccus denitrificans (APHA et al., 2012, Holt et al., 1994).

Tales estrategias requieren procesos separados y condiciones estrictamente controladas, lo cual hace que el proceso sea altamente costoso. Sin embargo, se ha demostrado que BOA quimiolitótrofas como $N$. europea, puede desnitrificar nitrito por medio de una nitrito reductasa en condiciones anaeróbicas, utilizando hidrógeno o compuestos orgánicos como donadores de electrones. También puede desnitrificar en condiciones aeróbicas, utilizando amonio como donador de electrones (Shaw et al., 2006).

Se han reportado varios estudios de bacterias heterótrofas cultivables, que pueden realizar nitrificación heterotrófica y desnitrificación aerobia en el mismo reactor y bajo las mismas condiciones, como es el caso de Pseudomonas sp., (Su et al., 2006), Bacillus sp., (Zhang et al., 2011), Pseudomonas putida (Kim et al., 2005) Rhodococcus sp. Chen et al., (2012) y Acinetobacter calcoaceticus (Yao et al., 2013).

En experimentos realizados por Chen et al., (2012), se aisló una bacteria de aguas residuales la cual fue caracterizada como Rhodococcus sp. Esta bacteria de morfología bacilar, Gram positiva, no móvil, que forma agregaciones filamentosas durante la fase inicial de crecimiento, demostró en experimentos con cultivos discontinuos aeróbicos, una remoción de $50 \mathrm{mg} / \mathrm{L}$ de nitrógeno amoniacal a las $16 \mathrm{~h}$ de incubación a $30^{\circ} \mathrm{C}$, lo cual equivale a una tasa de nitrificación de $3,1 \mathrm{mg} \mathrm{L}^{-1} \mathrm{~h}^{-1}$, superior a lo reportado en los estudios realizados por Zhang et al., (2011), donde obtuvieron tasas de remoción de 0,43 mg $\mathrm{L}^{-1} \mathrm{~h}^{-1}$, utilizando la bacteria Bacillus sp., superiores a las tasas de remoción de $1,15 \mathrm{mg} \mathrm{L}^{-1} \mathrm{~h}^{-1}$, alcanzadas en los experimentos realizados por Su et al., (2006) con la bacteria Pseudomonas sp. Análisis de nitratos y nitritos confirmaron que el nitrógeno amoniacal es convertido a nitritos y posteriormente 
a nitratos durante la fase de crecimiento de la bacteria. Consecuentemente, se evaluó la capacidad de nitrificación heterotrófica y la desnitrificación aeróbica que tiene Rhodococcus sp. en un reactor de $50 \mathrm{~L}$. Los resultados demostraron que el $85 \%$ del nitrógeno amoniacal $(100 \mathrm{mg} / \mathrm{L})$ fue transformado en nitratos y nitritos en un $13 \%$, nitrógeno intracelular en un $24 \%$ y productos de la desnitrificación en un $48 \%$ en $25 \mathrm{~h}$, obteniendo una tasa de remoción del amonio de $3,4 \mathrm{mg} \mathrm{L}^{-1} \mathrm{~h}^{-1}$. Se comprobó que la desnitrificación realizada por Rhodococcus sp., CPZ24, genera 99\% de $\mathrm{N}_{2}$ y $1 \%$ de $\mathrm{N}_{2} \mathrm{O}$, contribuyendo muy poco al efecto de invernadero.

Es probable que los aislamientos obtenidos en este estudio realicen nitrificación y desnitrificación, por lo tanto se recomienda evaluar la capacidad que tienen los aislamientos A7 y A15, para convertir los nitritos a nitratos, como también determinar los porcentajes de $\mathrm{N}_{2}, \mathrm{~N}_{2} \mathrm{O}, \mathrm{NO}_{2}$ y $\mathrm{NO}$ en condiciones aerobias y anaerobias y así determinar su potencial utilización para la remoción de compuestos nitrogenados en aguas residuales.

\section{CONCLUSIONES}

Se caracterizaron macroscópica, microscópica y bioquímicamente 16 aislamientos bacterianos de los cuales los aislamientos A1, A2, A7 y A15 se destacaron por oxidar el amonio a nitrito a $30^{\circ} \mathrm{C}$ durante 28 días. Los aislamientos A7 y A15 presentaron diferencias significativas frente a los demás aislamientos, al tener una mayor capacidad de oxidar amonio a nitrito en condiciones quimiolitotróficas. No obstante, se demostró que entre los aislamientos A7 y A15, no hubo diferencias significativas en cuanto a la oxidación del amonio. De acuerdo a las características ecofisiológicas, A15 y A7 son muy similares y podrían ser categorizados dentro del género Nitrosomonas sp. linaje 3a.

Los aislamientos bacterianos A15 y A7 podrían ser utilizados para implementar procesos que mejoren los tratamientos de aguas residuales, aumentando la eficiencia de remoción de contaminantes, especialmente de compuestos nitrogenados. 


\section{REFERENCIAS BIBLIOGRÁFICAS}

APHA. (2012). Standard Methods for the Examination of Water and Wastewater, 22th ed. American Public Health Association, Washington, DC, Estado Unidos de América. pp. 4-110, 4-125, 9-135.

Chaparro, T., y Ospina, I. (2005). Humedales de flujo vertical para mejorar la calidad del agua del río Bogotá. Ciencia e Ingeniería Neogranadina. 1 (15), 74-84.

Chen P, Li J., Li, QX., Wang, Y., Li, S., Ren, T., and Wang, L. (2012). Simultaneous heterotrophic nitrification and aerobic denitrification by bacterium Rhodococcus sp. CPZ24. Bioresource Technology, 116, 266-270.

Contreras, A., Pedrique, F., Bracho, N., y Fernández, P. (2009). Evaluación del potencial de remoción de nutrientes de un humedal artificial. Ciencia, 17 (3), 225-234.

De Jonge, V.N., Elliott, M., and Orive, E. (2002). Causes, historical development, effects and future challenges of a common environmental problem: eutrophication. Hydrobiologia , 475-476(1), 1-19.

Holt, J., Krieg, N., Snealth, N., Staley, J., and Williams, S. (1994). Bergey's Manual of Determinative Bacteriology. 9th ed. Baltimore, Maryland, Estados Unidos de America. William \& Wilkins Editors. pp. 448-455.

Kim, J.K., Park, K.J., Cho, K.S., Nam, S.W., Park T.K., and Bajpai, R. (2005). Aerobic nitrification-denitrification by heterotrophic Bacillus strains. Bioresource Technology, 96, 1897-1906.

Kouki, S., Saidi, N., M'hiri, F., Nasr, H., Cherif, H., Ouzari, H., and Hassen, A. (2011). Isolation and characterization of facultative mixotrophic ammonia-oxidizing bacteria from constructed wetlands. Journal of Environmental Sciences, 23(10), 1699-1708.

Lukow, T., and Diekmann, H. (1997). Aerobic denitrification by a newly isolated heterotrophic bacterium strain TL1. Biotechnology Letters, 19(11), 1157-1159.

Madigan, M.T., Martinko, J.M., y Parker, J. (2009). Brock Biología de los microorganismos. 8th ed. Madrid, España. Prentice Hall, 986p.

Otálora, A. (2011). Evaluación del sistema de tratamiento de aguas residuales domésticas mediante humedales artificiales de alta tasa en la locación petrolera de caño gandúl. Recuperado [16 de Julio 2013]. Disponible en < http://www.bdigital.unal.edu.co/5044/1/292544.2011.pdf> .

Padhi, S.K. Tripathy, S. Sen, R. Mohanty, S. Maiti, N.K. (2013). Characterization of heterotrophic nitrifying and aerobic denitrifying Klebsiella pneumoniae CF-S9 strain for bioremediation of wastewater. International Biodeterioration \& Biodegradation, 78, 67-73. 
Pommerening-Röser., and Koops H-P. (2005). Environmental pH as an important factor for the distribution of urease positive ammonia-oxidizing bacteria. Microbiological Research, 160, 27-35.

Qiu, X., Wang T., Zhong, X., Du, G., and Chen J. (2012). Screening and characterization of an aerobic nitrifying-denitrifying bacterium from activated sludge. Biotechnology and Bioprocess Engineering, 17(2), 353-360.

Rodríguez, M. Toro, L. Martínez, M. y Mercado M. (2007). Estandarización de condiciones para la prueba cuantitativa del NMP con bacterias nitrificantes y denitrificantes usando como matriz compost. Universitas Scientiarum, 12(2), 69-81.

Shaw, L., W., Nicol, G., Jon, Z., Prosser J., and Baggs E. (2006). Nitrosospira spp. can produce nitrous oxide via a nitrifier denitrification pathway. Environmental Microbiology, 8 (2), 214-222.

Su, J.J., Yeh, K.S., and Tseng, P.W. (2006). Strain of Pseudomonas sp. Isolated from piggery wastewater treatment systems with heterotrophic nitrification capability in Taiwan. Current. Microbiology, 53, 77-81.

Yao, S., Ni, J, Ma, T., and Li Can. (2013). Heterotrophic nitrification and aerobic denitrification at low temperature by a newly isolated bacterium, Acinetobacter sp. HA2. Bioresource Technology. 139, 80-86.

Zhang, J., Wu, P., Hao, B., and Yu, Z. (2011).Heterotrophic nitrification and aerobic denitrification by the bacterium. Pseudomonas stutzeri YZN-001.2011. Bioresource Technology, 102(2), 9866-9869.

Zhao B., He, Y.L., Hughes, J., and Zhang X.F. (2010). Heterotrophic nitrogen removal by a newly isolated Acinetobacter calcoaceticus HNR. Bioresource Technology. 101, 5194-5200. 


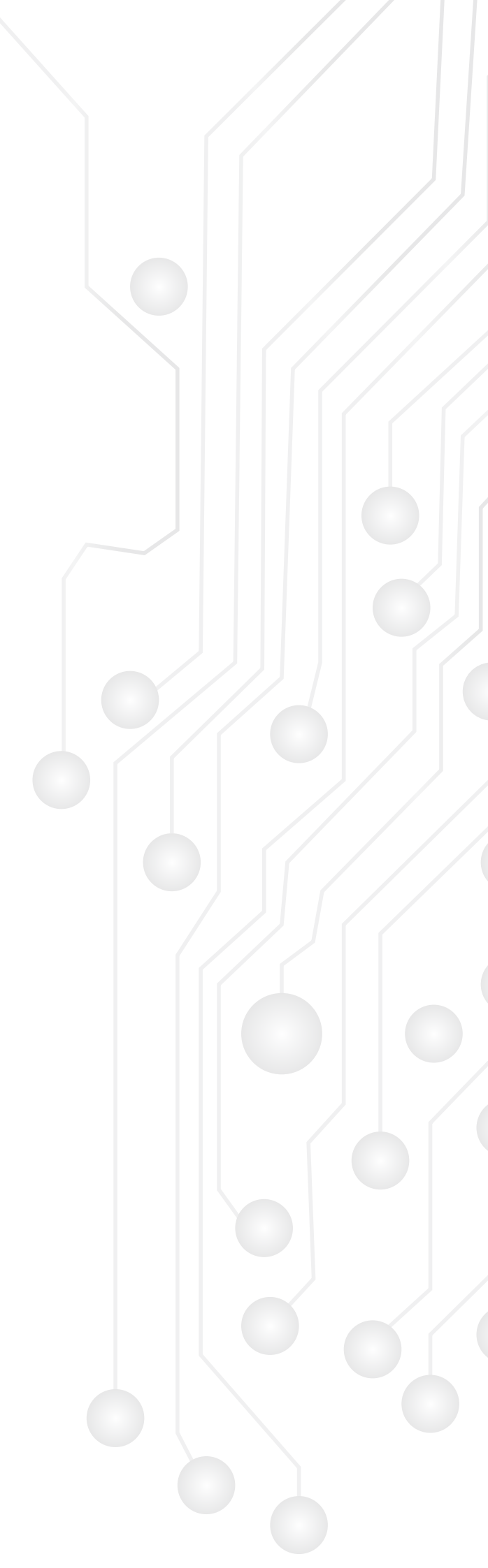

